\title{
Impact of Boundary-Layer Processes on Near-Surface Turbulence Within the West African Monsoon
}

\author{
Fabienne Lohou - Frédérique Saïd - Marie Lothon • \\ Pierre Durand • Dominique Serça
}

\begin{abstract}
High frequency measurements of near-surface meteorological data acquired in north Benin during the 2006 West African monsoon seasonal cycle, in the context of the African Monsoon Multidisciplinary Analysis (AMMA) experiment, offer insight into the characteristics of surface turbulence in relation to planetary boundary-layer (PBL) processes. A wide range of conditions is encountered at the lower and upper limits of the PBL: (i) from water-stressed to well-fed vegetation, and (ii) from small to large humidity and temperature jumps at the PBL top inversion, due to the Saharan air layer overlying the monsoonal flow. As a result, buoyant convection at the surface and entrainment at the PBL top play very different roles according to the considered scalar. We show that, when the boundary-layer height reaches the shear level between the monsoonal and Harmattan flows, the temperature source and humidity sink at the boundary-layer top are sufficient to allow the entrainment to affect the entire boundary layer down to the surface. This situation occurs mainly during the drying and moistening periods of the monsoon cycle and affects the humidity statistics in particular. In this case, the humidity turbulent characteristics at the surface are no longer driven solely by buoyant convection, but also by entrainment at the boundary-layer top. Consequently, the Monin-Obukhov similarity theory appears to fail for the parameterisation of humidity-related moments.
\end{abstract}

Keywords Entrainment $\cdot$ Humidity spatial variability $\cdot$ Monin-Obukhov similarity theory · West African monsoon

F. Lohou $(\varangle) \cdot$ F. Saïd · M. Lothon · P. Durand · D. Serça

Université de Toulouse, UPS, LA (Laboratoire d'Aérologie) CNRS, LA (Laboratoire d'Aérologie),

14 avenue Edouard Belin, 31400 Toulouse, France

e-mail: fabienne.lohou@aero.obs-mip.fr 


\section{Introduction}

Many processes in the planetary boundary layer (PBL) drive its diurnal evolution and its mean and turbulent characteristics. Among them, buoyant convection at the surface and entrainment at the PBL top are of primary importance and depend largely on the conditions at the lower and upper limits of the PBL. Unlike buoyant convection, entrainment remains a poorly quantified process (Conzemius and Fedorovich 2008). Nevertheless, several studies have pointed out the drying and warming effect of entrainment on the PBL, namely an increase in the PBL depth similar to that created by buoyant convection (e. g. Betts 2000; Santanello et al. 2007, among others). Beyond the mean value of the thermodynamic characteristics, entrainment also affects the turbulent characteristics of the PBL, especially the energy spectral shape.

Large-eddy simulation studies (Jonker et al. 1999, 2004; De Roode et al. 2004) have demonstrated the inflexible growth of the average spectral length with time according to the scalar vertical flux profile continuously evolving from a pure bottom-up to a pure topdown shape. Indeed, the average spectral length of the latter scalar reaches several times the PBL height. A numerical approach allows the study of extreme conditions that cannot be verified by experiment, as pure bottom-up and top-down scalars are rarely observed in the atmosphere.

However, the African Monsoon Multidisciplinary Analysis (AMMA) experiment (Redelsperger et al. 2006) provides an exceptional dataset over a wide range of PBL conditions, and provides the opportunity to study the effects of entrainment on turbulence close to the surface. The West African monsoon progresses northward with the intertropical convergence zone shift from the Guinean coast $\left(5^{\circ} \mathrm{N}\right)$ in March to around $20^{\circ} \mathrm{N}$ in July (linked with the apparent latitudinal movement of the sun). In the lower troposphere, two flows converge towards the so-called inter-tropical discontinuity at the surface: the northern Harmattan flow advecting warm and dry air from the Saharan air layer (SAL) and the moist and relatively cold monsoonal flow transporting oceanic air from the Guinean Gulf over the West African continent. A schematic of this situation is provided in Lafore et al. (2010). With the setting of the monsoon, deep convection occurs and rainy event occurrence increases, changing the surface moisture conditions and vegetation state. High frequency measurements, acquired at the surface in Benin over an entire annual cycle, sample the surface-layer characteristics of, (i) the SAL during winter with very dry conditions at the surface, (ii) the progressive setting of the monsoon with the overlying Harmattan flow and the vegetation state shifting from a water-stressed state to a well-fed state, and (iii) the moist full monsoon phase. Neither pure top-down nor bottom-up scalars are encountered here, but temperature, humidity and carbon dioxide concentration experience very diverse conditions.

An understanding of the West African monsoon relies partly on an improved study of the humidity distribution in the lower atmosphere and its evolution at different time scales (Bock et al. 2008; Lothon et al. 2008). Here, the turbulent time scale is investigated through use of the integral scale deduced from the turbulent part of the energy spectra (Lenschow and Stankov 1986; Kaimal and Finnigan 1994). Using this length scale, along with the variance and skewness, the fluctuation energy and spatial variability of humidity $(q)$, temperature $(T)$ and $\mathrm{CO}_{2}(c)$ at turbulence scales are examined for the West African monsoon cycle at the surface. Considering the very distinct signature of buoyant convection and entrainment on the turbulent characteristics of such scalars, the respective role of these two PBL processes, especially on humidity variability, is identified over the course of the year. This article, focusing on the surface layer, extends a study by Canut et al. (2010) on entrainment in the mixed layer, which uses airborne data acquired during AMMA (Saïd et al. 2010). 

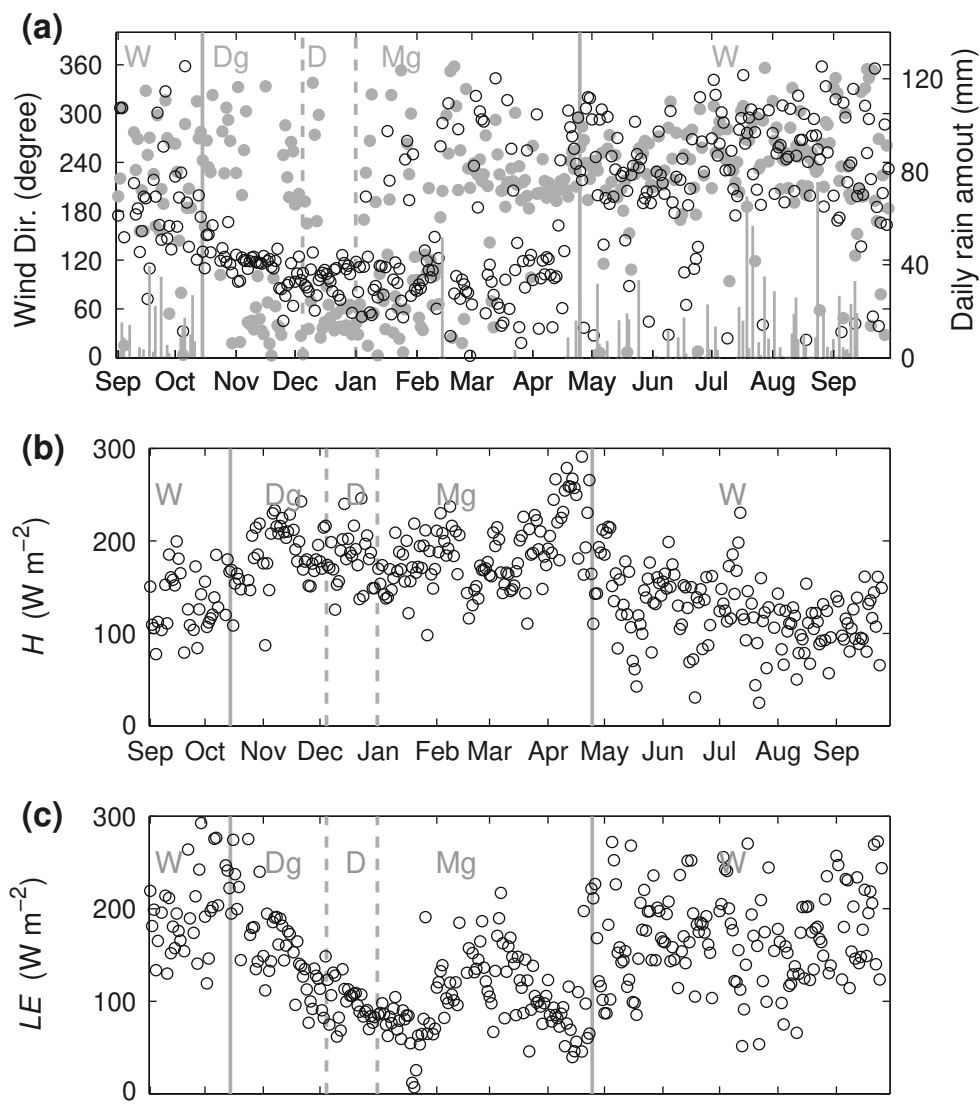

Sep Oct Nov Dec Jan Feb Mar Apr May Jun Jul Aug Sep

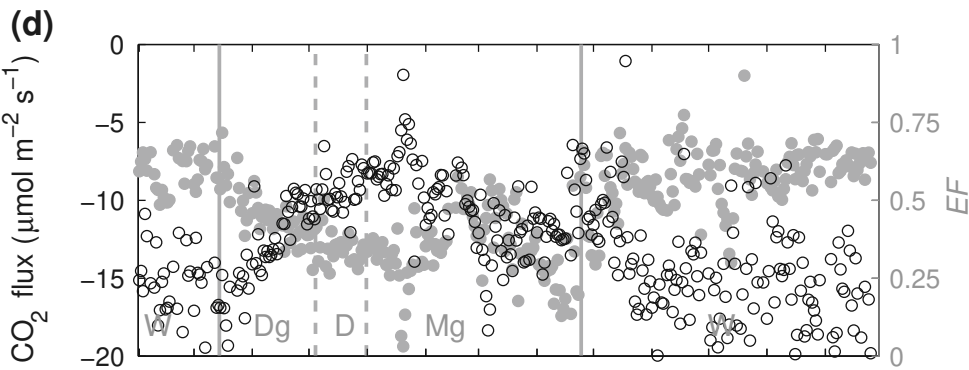

Sep Oct Nov Dec Jan Feb Mar Apr May Jun Jul Aug Sep

Fig. 1 Seasonal view over the Nangatchori site for: a wind direction averaged over nighttime (0000-0600 UTC) (solid grey circles) and daytime (1100-1700 UTC) (open circle); b surface sensible heat flux $(H)$, c surface latent heat flux ( $L E)$, d surface carbon dioxide vertical flux $\left(\mathrm{CO}_{2}\right.$ flux) (open circles) and evaporative fraction $(E F)$ (solid grey circles) averaged over 1000-1400 UTC. Rain events are indicated by bars in panel (a). $W, D g, D$ and $M g$ stand for wet, drying, dry and moistening periods, respectively

Following a description of the dataset used and the meteorological conditions in Benin (Sect. 2), the Monin-Obukhov similarity theory is applied to point out the dependence of the scalars on the surface conditions according to the season (Sect. 3). Two case studies from two 
different seasons allow us to illustrate the competition of the PBL bottom and top processes occurring during the PBL growth and their respective impacts on the turbulent characteristics of scalars (Sect. 4). A generalization to the seasonal cycle is made in Sect. 5.

\section{Dataset and Meteorological Context}

During the two-year (2005-2006) AMMA enhanced observation period, three meso-sites were implemented along a meridional transect (around $1^{\circ}$ E) crossing Benin, Niger and Mali. We use measurements made at Nangatchori, one of the ground stations of the southerly Ouémé meso-site in northern Benin $\left(1^{\circ} 44.46^{\prime} \mathrm{E}, 9^{\circ} 38.84^{\prime} \mathrm{N}\right)$. As UTC and local solar time are only $7 \mathrm{~min}$ apart at this site, the results will be henceforth presented according to UTC. The site is located in a Sudanian-Guinean vegetation-type area and the station was set up in a glade surrounded by woodland, crops and fallow, the vegetation of which had burnt in some areas during the previous 5 years. The station was equipped with numerous sensors that provided the temporal evolution of the chemical and meteorological variables of the low troposphere.

\subsection{In Situ Measurements}

As part of the experimental set-up, an $8 \mathrm{~m}$ high tower, operated by Laboratoire d'Aérologie, was equipped with a three-dimensional sonic anemometer (Gill) and an infra-red open-path gas analyser (Licor 7500) providing, at a 0.1-s time interval, "sonic" temperature and horizontal and vertical $(w)$ wind components, or water vapour mixing ratio $(q)$ and carbon dioxide $(c)$ concentrations, respectively. The first-, second- and third-order turbulence moments were calculated with the eddy-correlation method over 30-min samples. The true air temperature $(T)$ is computed from the sonic temperature corrected for its moisture component. The turbulent time series were detrended and a correction according to Webb et al. (1980) was applied to humidity and carbon dioxide vertical turbulent fluxes. Both instruments were operated on a continuous collection mode from 1 September 2005 to 4 April 2007. However, only one annual cycle from September 2005 to September 2006 is considered here.

\subsection{Wind Profiler}

For winds in the lower atmosphere we use observations from the Degréane UHF wind profiler owned by Météo-France and sited near the ground station. It operated continuously from 8 to 22 April 2006 and then from 4 August 2006 to April 2007. Unfortunately, a long period of sparse data and loss of sensitivity from 23 April to 4 August 2006 led to unusable data.

The UHF radar measures vertical profiles of wind and backscattered signal strength. In clear air the atmospheric signal is created by the backscattering by spatial irregularities of the air refractive index at a scale of half the radar wavelength. Therefore, the conjunction of strong turbulence and acute mean vertical gradients of temperature and humidity produces the strongest echoes. That is why the PBL top (at $z=z_{i}$ ) is usually marked by a maximum in the refractive index structure coefficient $\left(C_{n}^{2}\right)$ deduced from the radar reflectivity (Doviak and Zrnic 1993). This criterion is currently used to monitor the PBL height (Angevine et al. 1994). 
The observations made by the profiler are based on a repetitive sequence of about a 5-min cycle over the five beams that provide data from $75 \mathrm{~m}$ to $3 \mathrm{~km}$ a. g. 1 . with a vertical resolution of $150 \mathrm{~m}$. The data processing is detailed in Jacoby-Koaly et al. (2002).

\subsection{Meteorological Context}

The 2006 monsoon features were compared by Janicot and Sultan (2007) to a statistical description of the monsoon over two decades (1968-1990) (Sultan and Janicot 2003). The establishment of the monsoon in West Africa is governed by the inter-tropical convergence zone's migration to the north in spring and to the south in autumn. Around the end of June, its northward shift is interrupted by a temporary stagnation in latitude associated with a decrease in convective activity, called the monsoon onset. Sultan and Janicot (2003) centred this 2 -week monsoon onset period on 24 June \pm 8 days. In 2006 the onset was evaluated to about 10 days later and extended from 25 June to 10 July, centred on 3 July (Janicot and Sultan 2007).

Figure 1a presents nighttime (0000-0600 UTC) and daytime (1100-1700 UTC) averages of low-level wind direction and daily cumulated rain events at Nangatchori from September 2005 to September 2006. Based on the wind characteristics and on the temporal evolution of $T$ and $q$ near the surface, Lothon et al. (2008) divided the annual cycle into four periods, dry (December), moistening (January to April), wet (May to mid-October) and drying (midOctober to November), directly linked to the back and forth migration of the inter-tropical discontinuity. A westerly wind corresponds to the cold and moist monsoonal flow whereas an easterly wind is associated with the warm and dry Harmattan flow. The monsoonal flow is steadily settled during the entire wet season, which corresponds to the rainy period at that site (except for a one-off event in February). The rest of the annual cycle was divided into three periods (drying, dry and moistening) characterized by a progressive change in the wind direction from monsoon to Harmattan (drying period), followed by a short dry period with an easterly flow during the whole day and, lastly, a return to the monsoonal flow with a well-marked diurnal cycle during the moistening period discussed by Parker et al. (2005) and Lothon et al. (2008). In reality, at that time of year, a westerly wind is observed during the night whereas easterly conditions prevail during the day. These peculiar dynamical conditions are due to the diurnal back-and-forth movement of the inter-tropical discontinuity due to the large-scale forcing (horizontal temperature gradient across the continent) and vertical development of the boundary layer.

The seasonal evolution of surface sensible $(H)$ and latent $(L E)$ heat fluxes, carbon dioxide vertical flux $\left(\mathrm{CO}_{2}\right.$ flux) and evaporative fraction $(E F)$, averaged between 1000 and 1400 UTC, is presented in Fig. 1b, c, and d, respectively. The evaporative fraction is defined as:

$$
E F=\frac{L E}{H+L E},
$$

and during the wet season, $E F$ is around 0.6-0.7. A large scattering of $E F$ is observed from May to mid-July, which corresponds to sparse rain events leading to varying surface moisture. The increased occurrence of rain events after mid-July (monsoon onset) results in steadier surface characteristics and evaporative fraction.

The dry period starts when the inter-tropical discontinuity passes south to Nangatchori and is characterized primarily by a slow, continuous decrease in $E F$ from 0.6 to 0.3 over 3 months (November, December and January). An isolated rain event in February leads to an increase in $E F$ before it decreases again in March and April. The annual variation at higher latitude [in Niger (Ramier et al. 2009) and Mali (Timouk et al. 2009)] can be much sharper 
than in Benin, where the persistence of the vegetation photosynthetic activity throughout the year results in a smoother decrease of $L E$ after the wet season. The evolution of the $\mathrm{CO}_{2}$ flux over the course of the year is perfectly out of phase with $E F$, due to their close link with vegetation activity.

The seasonal shift of the inter-tropical discontinuity alters the dynamical and thermodynamical features of the lower troposphere considerably. In order to illustrate the wide range of conditions encountered over the year within and above the PBL, three examples of radiosonde profiles (from the surface up to $3 \mathrm{~km}$ ) of potential temperature $(\theta$ ), humidity and wind direction are shown in Fig. 2. These sondes were launched in Parakou, 100 $\mathrm{km}$ east of Nangatchori. On 26 December 2005, the inter-tropical discontinuity is south of Nangatchori and a very homogeneous and dry $\left(3-4 \mathrm{~g} \mathrm{~kg}^{-1}\right)$ Harmattan flow is well settled down to the surface (dry season example). The inversion at $1200 \mathrm{~m}$ does not show any decrease in humidity, because at that time of the year the surface is very dry, evaporation is weak and the PBL water vapour content is therefore very small. The day of 12 April 2006, during the moistening season, illustrates the progressive northward shift of the inter-tropical discontinuity, with the monsoonal flow penetrating below the SAL. Profiles of potential temperature and water vapour mixing ratio show the large contrast between the two flows. The PBL top reaches $1100 \mathrm{~m}$ at $1200 \mathrm{UTC}$ and is capped by a large moisture decrease of $10 \mathrm{~g} \mathrm{~kg}^{-1}$ and a potential temperature increase of $7^{\circ} \mathrm{C}$. Thus a dry layer caps the PBL that develops within the monsoonal flow. Lastly, the day of 31 July 2006 is representative of the wet period after the monsoon onset, with moister levels up to $3 \mathrm{~km}$ and a shallower PBL. During that period, the PBL top barely reached $1 \mathrm{~km}$.

\section{Monin-Obukhov Similarity Theory}

The Monin-Obukhov similarity theory (MOST) is widely used to merge diverse near-surface observations through universal functions and, in doing so, to demonstrate success of the theory. The method consists of predicting the relationship between normalized turbulent moments and $z / L$, where $z$ is the measurement height and $L$ is the Obukhov length defined as (Stull 1988),

$$
L=-\frac{u_{*}^{3} \bar{\theta}_{v}}{k g \overline{w^{\prime} \theta_{v}^{\prime}}},
$$

where $u_{*}$ is the friction velocity $\left(u_{*}^{2}=-\overline{w^{\prime} u^{\prime}}\right), \theta_{v}$ is the virtual potential temperature, $k$ is the von Karman constant and $g$ is the gravitational acceleration. Primes represent fluctuations from the mean.

In the present study, the variation of the turbulent structure in the surface layer is depicted in the following sections through the use of the standard deviation, integral scale and skewness of $w, T, q$, and $c$. The relationships of these three turbulent characteristics with $z / L$ are studied to test their dependence on the surface forcing.

The standard deviation $\sigma_{x}$ of a variable $x$ is normalized in the MOST by the $x$ flux scale. Therefore $\sigma_{w}, \sigma_{T}, \sigma_{q}$, and $\sigma_{c}$ are divided, respectively, by $u_{*},\left|T_{*}\right|,\left|q_{*}\right|,\left|c_{*}\right|$, where $-u_{*} T_{*}=\overline{w^{\prime} T^{\prime}},-u_{*} q_{*}=\overline{w^{\prime} q^{\prime}}$ and $-u_{*} c_{*}=\overline{w^{\prime} c^{\prime}}$.

The integral scale $l_{x}$ is a length scale (we assume Taylor's hypothesis) over which $x$ remains relatively correlated to itself, and is defined from the autocorrelation function $R_{x}$. It is considered representative of the energy-containing eddies. However, several studies (Lenschow and Stankov 1986; Durand et al. 2000) found the integral scale to be 2-6 times 
Fig. 2 Three examples of $\mathbf{a}$ potential temperature, $\mathbf{b}$ water vapour mixing ratio and $\mathbf{c}$ wind direction from radiosondes launched at Parakou at 1200 UTC on 26 December 2005 (solid line), 12 April 2006 (dashed line), and 31 July 2006 (dashed-dotted line)
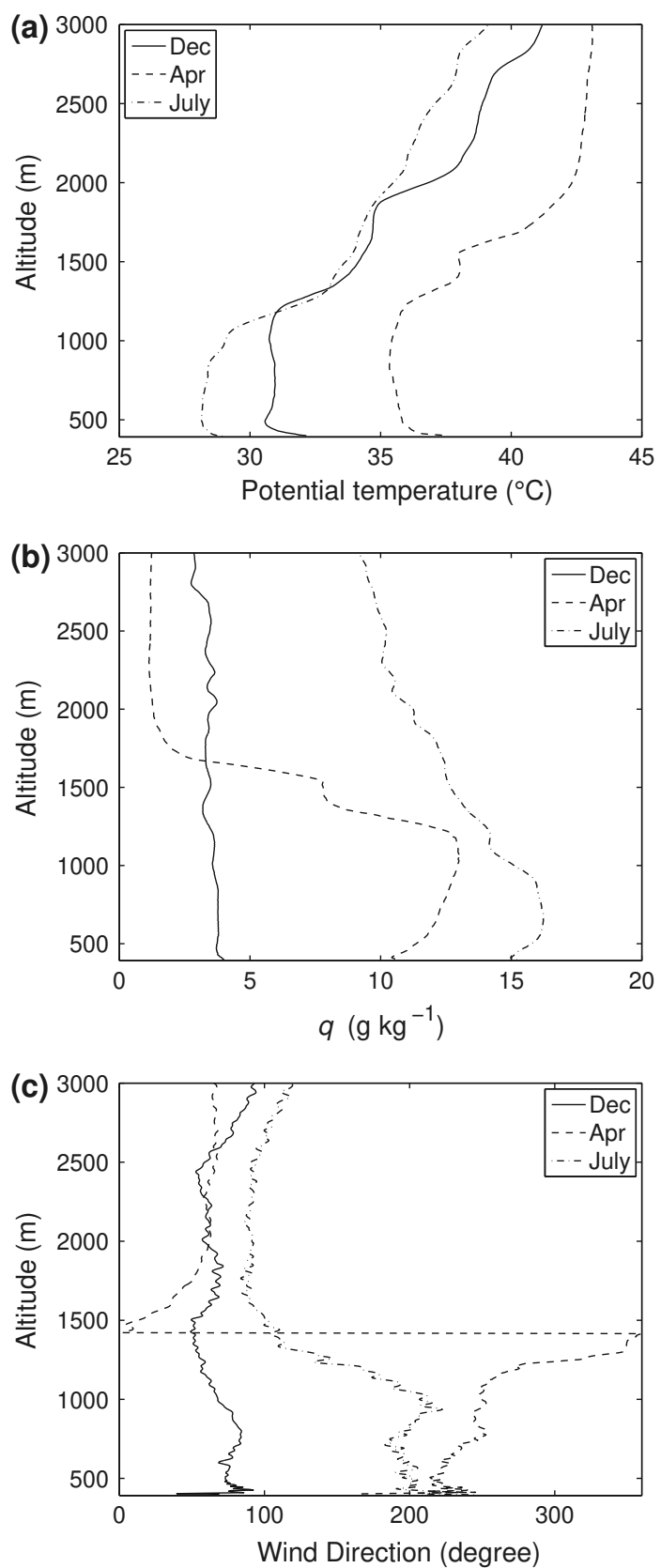

smaller than the wavelength of the energy spectrum peak. This ratio varies according to the shape of the spectra at the transition between low frequencies and the inertial subrange [called the spectral knee by Lenschow and Stankov (1986)], which depends on the measurement height and the variable $x$. Therefore, a change in the spatial variability of $x$ at small scales results in a change in the integral scale. The integral length scale $l_{x}$ can be written as: 


$$
l_{x}=U \int_{0}^{\infty} R_{x}(\tau) d \tau,
$$

where $U$ is the time-space conversion velocity (mean wind here), according to Taylor's frozen turbulence hypothesis, and $\tau$ is the temporal separation. The integral scales of cross second-order moments $\left(l_{w x}\right)$ can also be computed from the autocorrelation function $R_{w x}$ of the instantaneous covariance. $l_{x}$ is often estimated over a restricted integration from zero lag to the first zero of $R_{x}$ (Lenschow and Stankov 1986). However, the integral scale estimation must be applied with caution, due to the limit of the one-dimensional spectrum $S_{x}(f)$ when the frequency $f$ tends to zero. A sample selection, based on spectra shape, has been applied to Nangatchori data (see Appendix for details). The integral scale in the surface layer should be normalized by $L$, but in order to avoid the intrinsic correlation between $l_{x} / L$ and $z / L$, the dimensional $l_{x}$ is plotted against $z / L$.

The skewness $S_{x}$ is the normalized third-order moment defined as:

$$
S_{x}=\frac{\overline{x^{\prime 3}}}{\bar{x}^{\prime 2} 3 / 2},
$$

and provides clues as to the transport and origin of the scalars. Vertical profiles of $S_{x}$ in the lower troposphere can be obtained using aircraft measurements (Druilhet et al. 1983; Crum and Stull 1987; Canut et al. 2010). Several studies use skewness as an indicator of top-down transport through entrainment processes at the PBL top in opposition to the bottom-up transport of the buoyant convection (Mahrt 1991; Lenschow et al. 2002; de Arellano et al. 2004; Couvreux et al. 2007; Lothon et al. 2007).

In Figs. 3, 4 and 5, the normalized standard deviation, integral scales and skewness are plotted against $-z / L$ distinctly for wet and dry (W-D) and drying and moistening (Dg-Mg) seasons. The turbulent moments and $L$ are averaged over 1000-1400 UTC, but the same trends are found using other averaging periods, such as turbulent moments estimated over 30-min sample and averaged over bins of $L$. Non-dimensional standard deviations of $w, T$ and $q$ as a function of stability have been studied many times, whereas the application of MOST for carbon dioxide concentration is rarely seen. The fitted curves over-plotted are those found by Andreas et al. (1998) and are very similar to those generally reported in the literature. They fit normalized $\sigma_{w}, \sigma_{T}$ and $\sigma_{c}$ very well, whatever the season. An exception is noted for the $\sigma_{q} /\left|q_{*}\right|$ large scatter, which is mostly due to the $\mathrm{Dg}-\mathrm{Mg}$ data (this difference between $\mathrm{Dg}-\mathrm{Mg}$ and $\mathrm{W}-\mathrm{D}$ seasons is discussed in Sects. 4 and 5). Integral scale and skewness are rarely submitted to MOST, but despite the large scatter, one notes a clear relationship between statistical quantities and stability for $T$ and $c: l_{T}$ and $l_{c}$ are lower in unstable conditions with a corresponding absolute value in skewness increasing close to unity. One might have expected an opposite trend, implying an increase of the integral scale with instability, although no results in the literature show this. Actually, the integral scale might evolve as the wavelength of the energy spectrum peak against $z / L$ in the surface layer as is the case in the mixed layer. But, in contrast to stable conditions, no universal laws have been found for the wavelength of the energy spectrum peak both for the horizontal wind components and the temperature in unstable conditions (Kaimal and Finnigan 1994, p. 43). The relationship for $q$ statistics with $-z / L$ tends to be the same as $T$ during the W-D seasons, despite a much larger scatter. In the $\mathrm{Dg}-\mathrm{Mg}$ season $l_{q}$ and $S_{q}$ do not follow any universal law.

Uncertainties in some of the MOST universal functions have already been pointed out and may be associated with the effects of a heterogeneous surface. As in our study, Andreas et al. (1998) found that the statistics involving humidity do not follow MOST, contrary to 

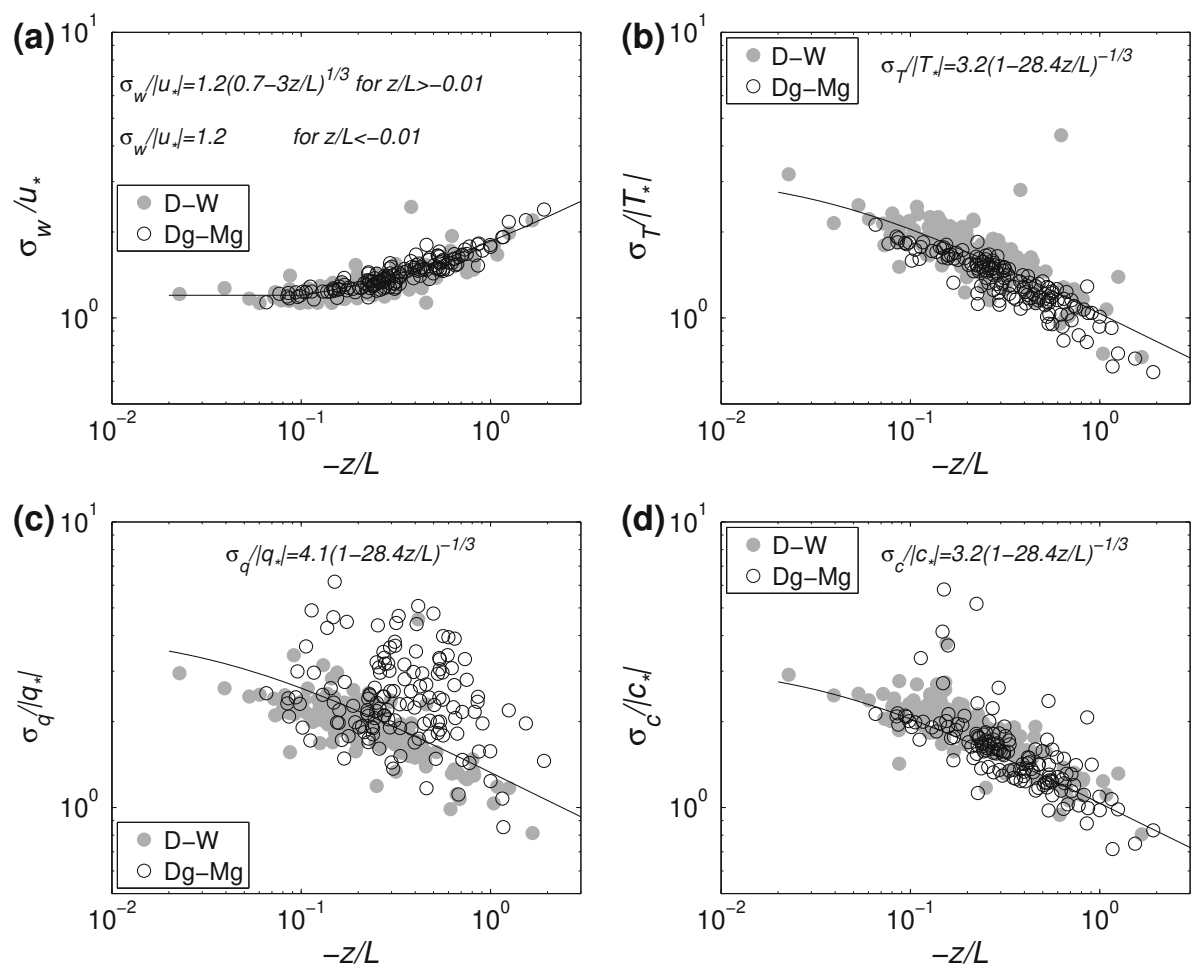

Fig. 3 Averaged daytime (1000-1400 UTC) normalized standard deviation of a $w$, b $T$, c $q$, and d $c$ as a function of $-z / L$ for wet and dry (W-D) (solid grey circles) and drying and moistening (Dg-Mg) (open circles) seasons. Solid lines and corresponding equations are the MOST laws found by Andreas et al. (1998)

those involving temperature, and explained the difference between the two scalars in terms of surface heat sources homogeneously distributed compared to the surface humidity sources. Using a two-year dataset of atmospheric surface-layer measurements conducted above a Mediterranean ecosystem in Sardinia (Italy), Detto et al. (2008) explained the departure of moisture and carbon dioxide variances from Monin-Obukhov scaling during dry conditions as due to surface heterogeneities, and also entrainment at the top of the boundary layer. As noted by Moene et al. (2006), MOST is accurate so long as the dominant driving force is included in the scale that is used to normalize the scalar statistics. The latter authors indicated that, at the PBL top, entrainment is a determinant forcing and should be included in the normalization parameter. This is likely to hold true in the surface layer as well if entrainment is sufficient to affect the PBL down to the surface.

\section{Diurnal Cycle of Bottom and Top PBL Processes}

Two case studies have been chosen to illustrate the difference between the $\mathrm{W}-\mathrm{D}$ and $\mathrm{Dg}-\mathrm{Mg}$ seasons, when attempting to apply MOST. The 20 April case follows the third rain event of the season (except for the one-off rainfall in February) that occurred on 19 April around 2100 UTC (the accumulated rainfall was $9 \mathrm{~mm}$ ). This day is at the end of the moistening season, humid conditions prevail at the surface, but the brief rainfall only allows the surface to dry 

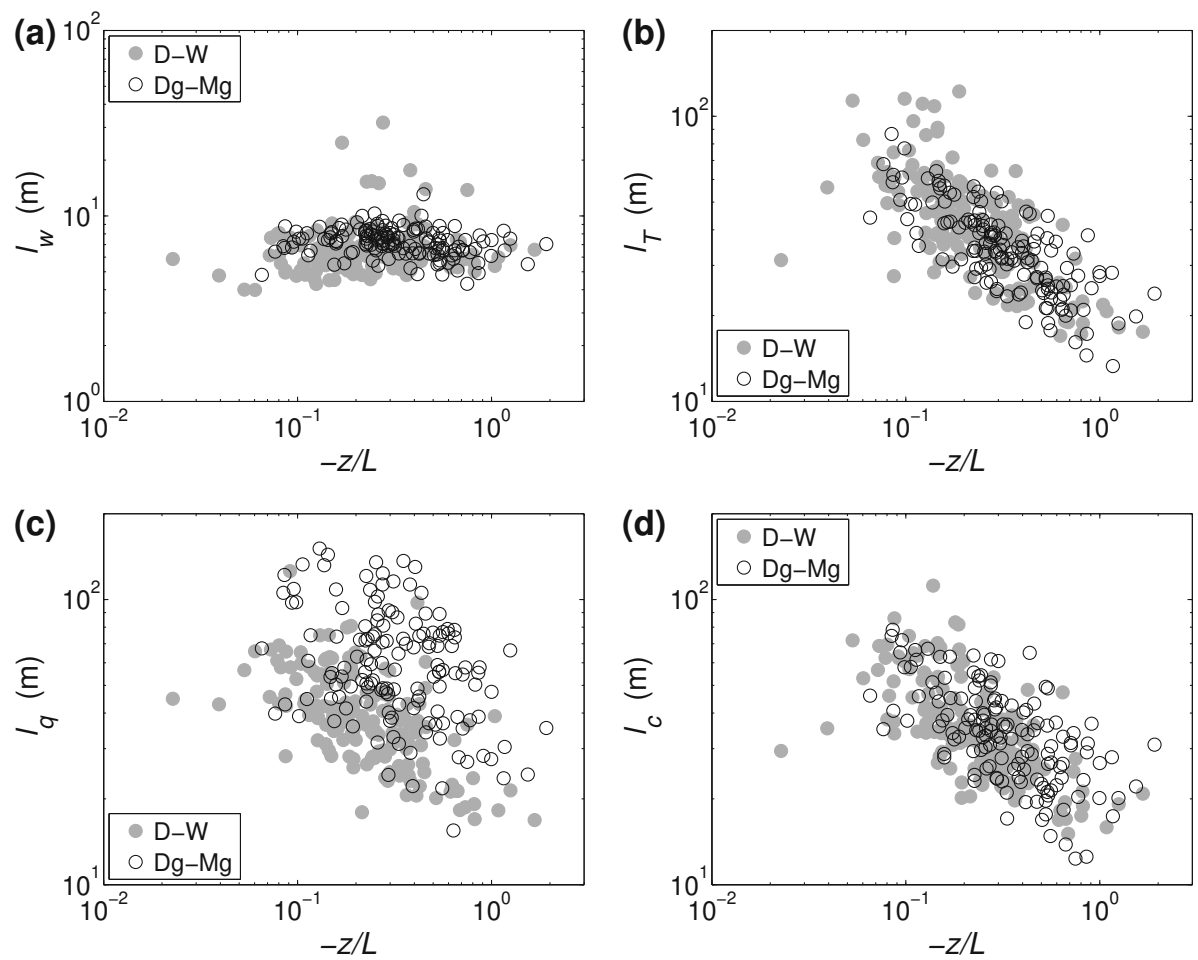

Fig. 4 Averaged daytime (1000-1400 UTC) integral scale $\mathbf{a} l_{w}, \mathbf{b} l_{T}, \mathbf{c} l_{q}, \mathbf{d} l_{c}$ as a function of $-z / L$ for wet and dry (W-D) (solid grey circles) and drying and moistening (Dg-Mg) (open circles) seasons

during the following days. In contrast, the 16 September case is at the end of the wet season, in quite different conditions: moist air, wet ground and well water-fed vegetation. Buoyant convection at the surface and entrainment at the PBL top will be shown to have different impacts during the diurnal growth of the PBL during these 2 days. The competition between these two PBL processes at the surface is depicted by use of the integral scale.

The time-height cross-section of the 1-h running mean wind speed measured by the UHF wind profiler shows a 1-km deep monsoonal flow throughout the day, capped by the easterly wind of the SAL in both cases (Fig. 6a, b). On the 20 April, the PBL top at $z=z_{i}$, depicted by $C_{n}^{2}$ maxima, slowly rises from $500 \mathrm{~m}$ to $1,000 \mathrm{~m}$ within the monsoonal flow until 1200 UTC (Fig. 6a). Between 1200 and 1330 UTC, the PBL height levels out at around the shear level $z=z_{s}$ between the cold/moist monsoon and the warm/dry easterlies above. As soon as the PBL top reaches the SAL, the PBL grows rapidly up to $2.5 \mathrm{~km}$ within $2.5 \mathrm{~h}$. On 16 September, the PBL top reaches $1,000 \mathrm{~m}$ at 1200 UTC but remains below $z=z_{s}$ all day.

These two situations are similar during the morning, with a PBL developing within the monsoonal flow. But these cases diverge after noon, probably because in April the sensible heat flux is large enough $\left(200 \mathrm{~W} \mathrm{~m}^{-2}\right)$ to allow the PBL top to reach and overshoot the height $z=z_{s}$ and the temperature jump between the monsoonal and Harmattan flows after 1330 UTC, and even to surpass that height afterward. In contrast, in September the sensible heat flux is too small $\left(100 \mathrm{~W} \mathrm{~m}^{-2}\right)$ for the PBL to become deeper than the monsoonal flow. On 20 April, entrainment is expected to have a significant impact on turbulence characteristics at the surface between 1200 and 1330 UTC. Subsequently, the upper part of the boundary layer 

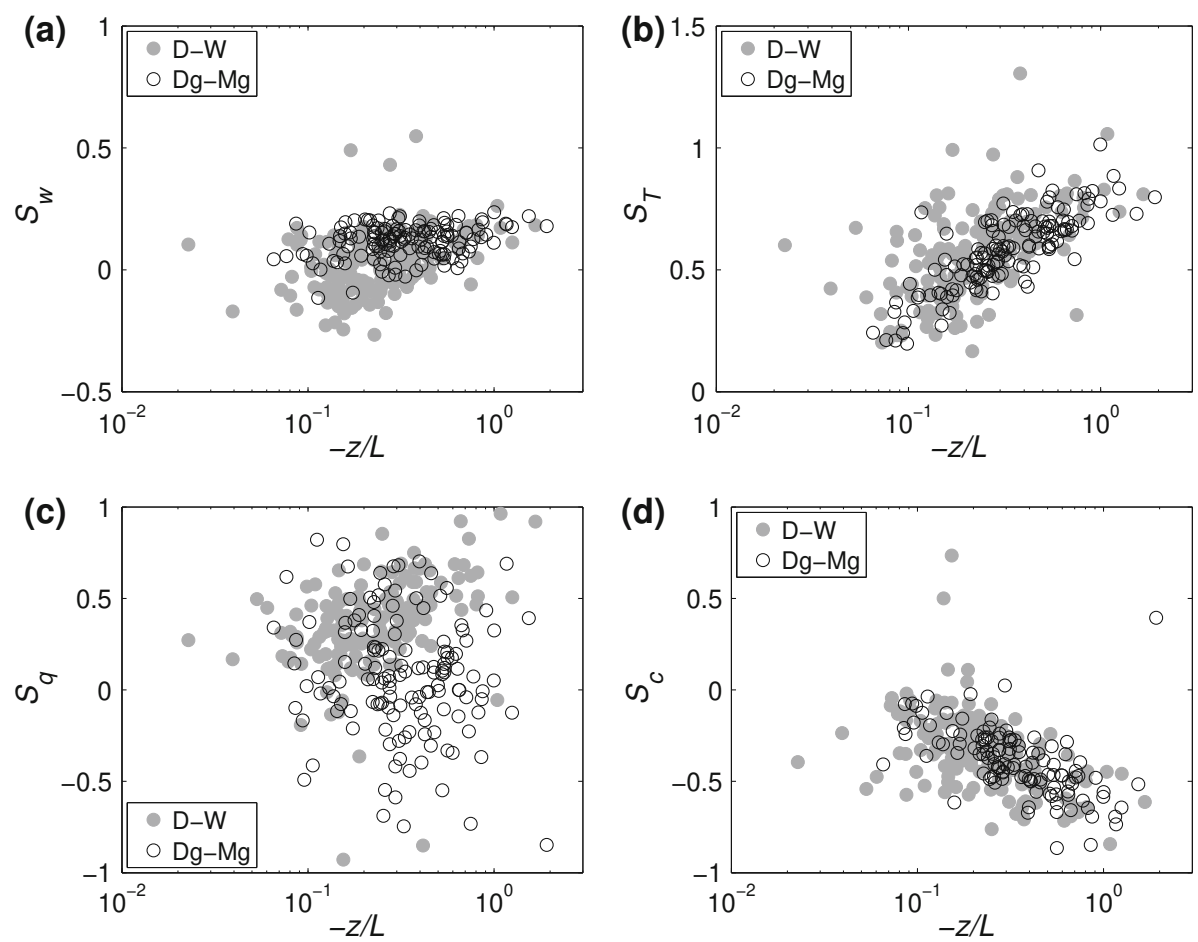

Fig. 5 Averaged daytime (1000-1400 UTC) skewness a $S_{w}$, b $S_{T}$, c $S_{q}$, d $S_{c}$ as a function of $-z / L$ for wet and dry (W-D) (solid grey circles) and drying and moistening (Dg-Mg) (open circles) seasons

develops in the SAL, mixing monsoonal and SAL air masses together, producing a decrease in the humidity and temperature jumps across the PBL top.

The surface temperature and humidity time series are plotted in Fig. 7a and b. A sharp decrease of $4.5 \mathrm{~g} \mathrm{~kg}^{-1}$ is observed in the specific humidity between 1200 and 1300 UTC on 20 April indicating a mixing of SAL dry air within the PBL. No change in humidity can be noted for the 16 September. On 20 April, the change in the integral scale is obvious for the three variables $q, T$ and $c$ exactly when $z_{i}=z_{s}$ at 1200 UTC (Fig. 7c). The normalized integral scales are very small so long as the PBL grows within the monsoonal flow, and during that time, there is no significant sink of humidity above the PBL. Buoyant convection, through the surface fluxes, is the dominant process that determines the turbulence structure in the surface layer. However, after 1200 UTC, a dryer and warmer sheared layer caps the PBL, inducing a strong source of heat and sink of humidity that modifies, through entrainment, the integral scales of temperature, carbon dioxide, and especially humidity (Note that $l_{w}$ is not affected and remains small at the transition (not shown)). Whereas turbulent convection is characterized by small turbulent scales, the entrainment scales are larger and close to those of the coherent upward currents, or to the PBL inter-cloud spacing (Nicholls and LeMone 1980). On the contrary, there is no effect on the September case integral scales, which remain governed by buoyant convection throughout the day (Fig. 7d).

Finally, the evaporative fraction (Fig. 7e) decreases from 0.7 to 0.5 between 0900 and 1400 UTC for the April case. This evolution results from the gradual decrease of the vegetation transpiration related to increasing water stress. Nevertheless, a stronger decrease is observed 

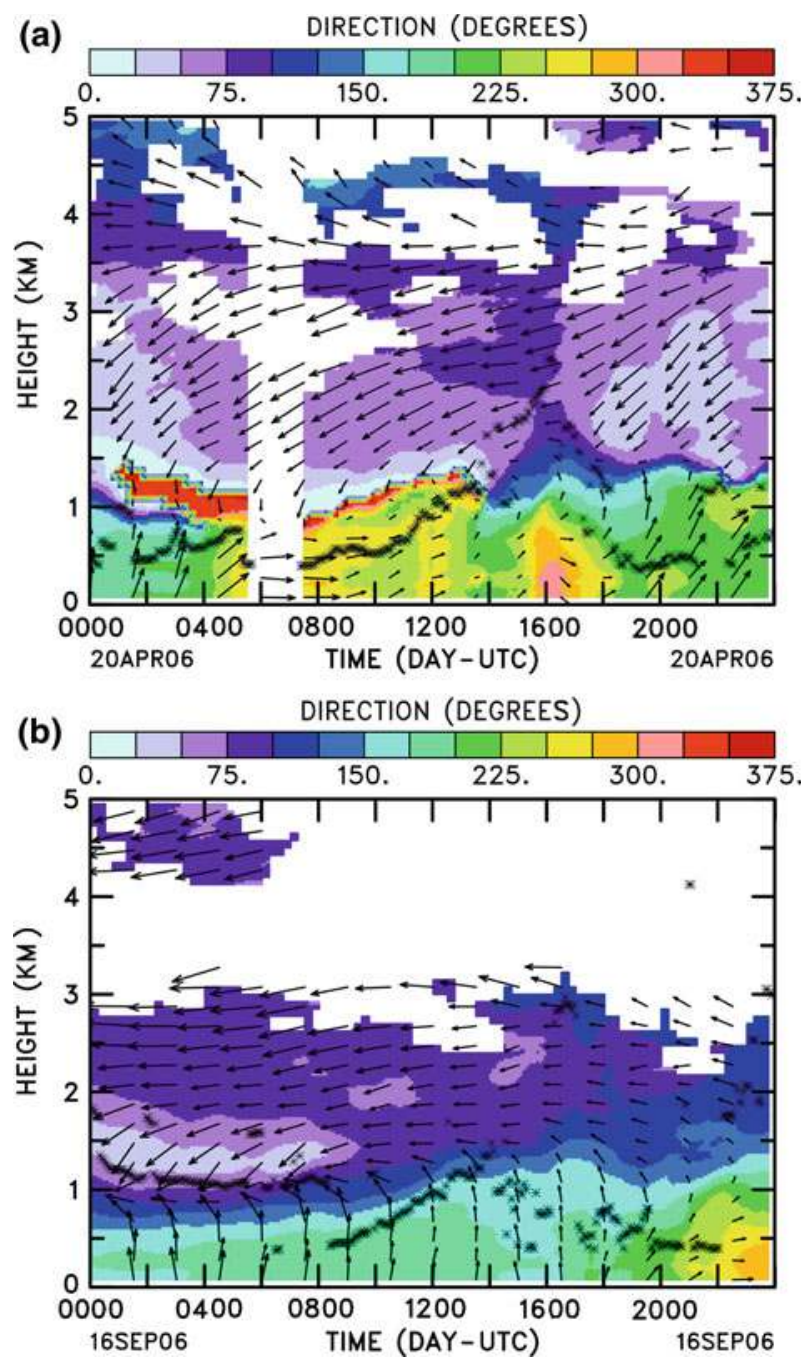

Fig. 6 Time-height section of horizontal wind and PBL depth (stars) measured by the UHF wind profiler in Nangatchori on a 20 April and b 16 September 2006. In both panels, the colour scale indicates the wind direction (in degrees), and the arrows stand for the horizontal wind (downward arrow for northerly wind)

between 1200 and 1300 UTC, when the entrainment process exerts an additional stress on the vegetation as the PBL dries out. The evaporative fraction has a very different evolution on 16 September, increasing in the morning and levelling in the afternoon (Fig. 7f). The vegetation is affected neither by the lack of water in the soil nor by the PBL drying due to entrainment.

\section{Seasonal Variability of Turbulence Characteristics}

The seasonal evolution of the standard deviation, integral scale and skewness of $q, T$ and $c$ averaged for the period 1000-1400 UTC is presented in Figs. 8, 9 and 10, respectively. 


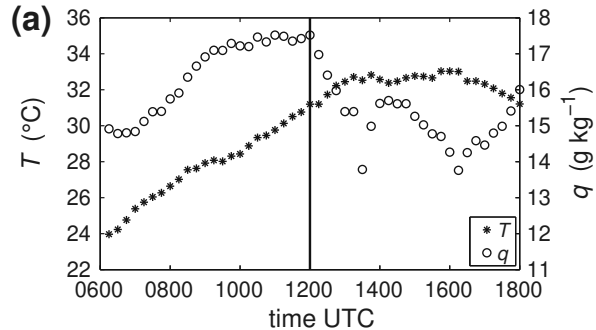

(c)
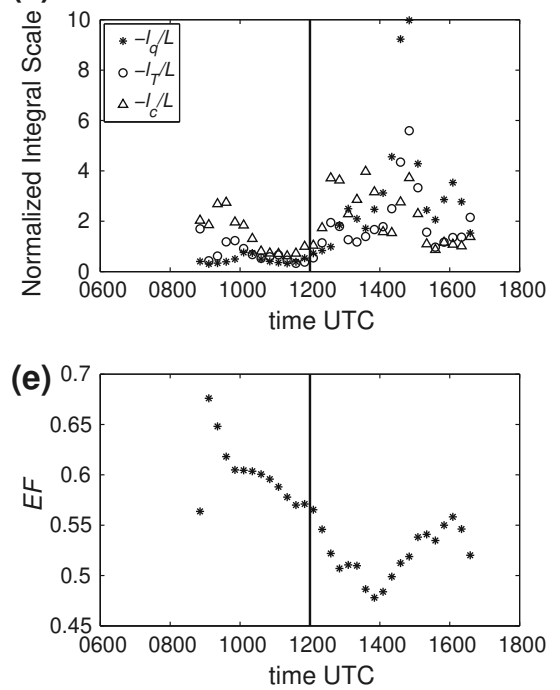

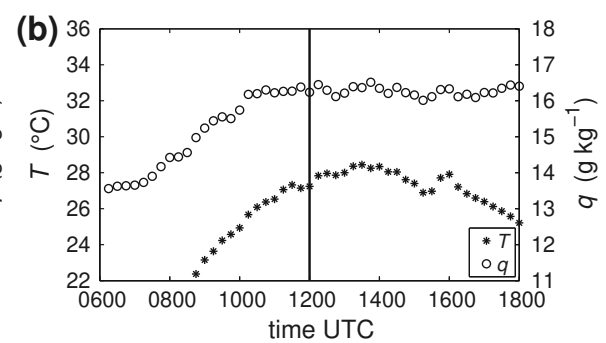

(d)
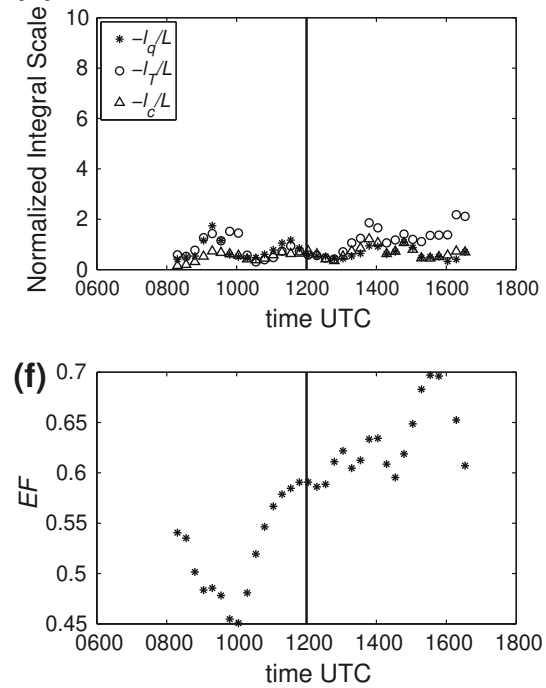

Fig. 7 Diurnal evolution of $\mathbf{a}, \mathbf{b}$ temperature and humidity, $\mathbf{c}, \mathbf{d}$ normalized integral scale of $q, T$ and $c$, and e, f evaporative fraction measured near the surface, on 20 April 2006 (left panels) and 16 September 2006 (right panels)

Integral scales and standard deviations are plotted both normalized and not normalized; means and standard deviations of $l_{q}, l_{T}, l_{c}, l_{w}, l_{w T}$ and $l_{w q}$ are indicated in Table 1 for the $\mathrm{W}-\mathrm{D}$ and $\mathrm{Dg}-\mathrm{Mg}$ seasons.

The integral scale $l_{q}$ has a clear seasonal evolution with most of its values smaller than $50 \mathrm{~m}$ during the wet season and associated with positive skewness (Fig. 8). Out of the wet period, $l_{q}$ is twice as large and scattered as during the wet period. The corresponding skewness, whether positive or negative, is small. The normalization by the Obukhov length does not flatten out this seasonal behaviour in the $\mathrm{Dg}-\mathrm{Mg}$ season, which is consistent with the low correlation found between $l_{q}$ and $-z / L$ at that time (see Fig. $4 \mathrm{c}$ ). However, as expected, the normalization leads to very small values of $l_{q} / L$ during the dry period of December and January when the Harmattan is settled in the low troposphere down to the surface. The standard deviation $\sigma_{q}$ is $0.35 \mathrm{~g} \mathrm{~kg}^{-1}$ on average and, surprisingly, does not depart significantly from this value throughout the year except during the dry season. Thus, the seasonal evolution of $\sigma_{q}$ does not follow that of $L E$ and $E F$. This indicates that humidity turbulent fluctuations are induced by turbulent sources that are different from those at the surface during the $\mathrm{Dg}-\mathrm{Mg}$ season. This result is supported by zero or negative skewness at that time. 

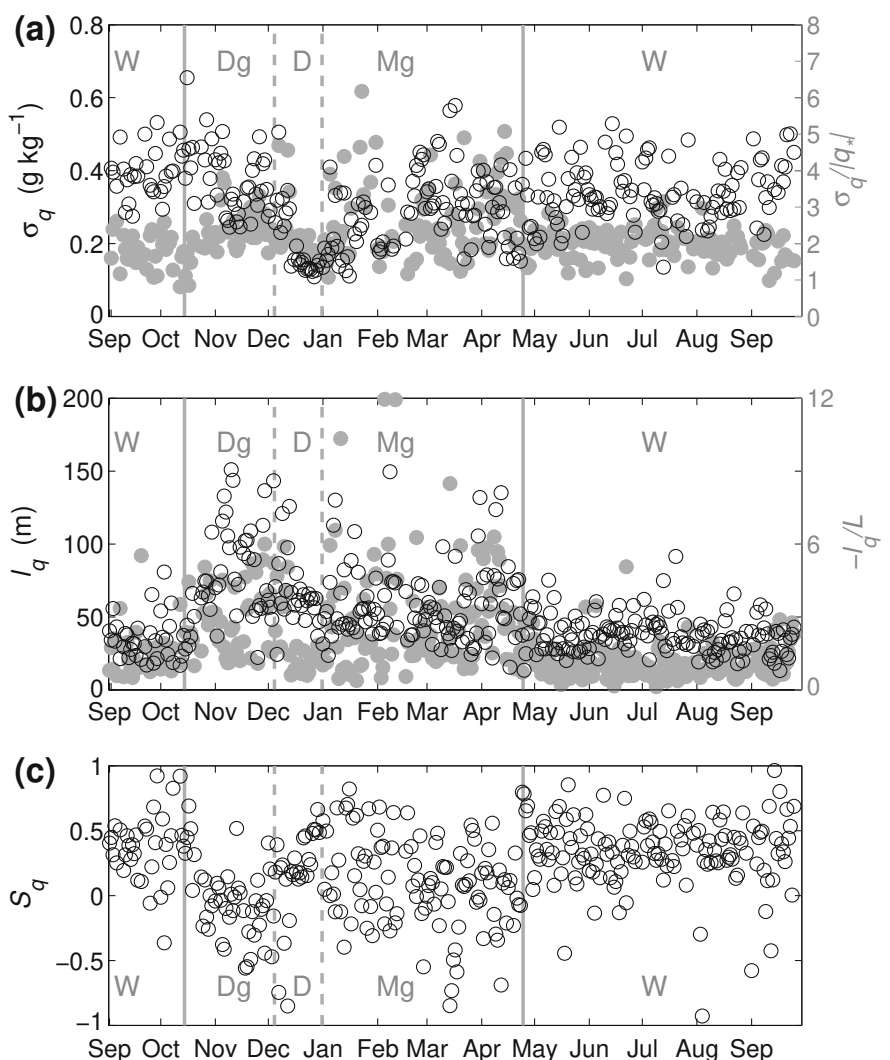

Fig. 8 Time series of 1000-1400 UTC mean values of $q$ dimensional (open circles) and normalized (solid grey circles) a standard deviation, b integral scale, and c skewness over Nangatchori site from September 2005 to September 2006

Slightly larger values of $l_{T}$ are observed during the W-D season with larger variability than during the Dg-Mg season (Fig. 9; Table 1). However, the normalization by $L$ has a large effect and flattens out the trend, which confirms the dependence of $l_{T}$ on near-surface conditions throughout the year (see Fig. 4b). As expected, $S_{T}$ retains the same order of magnitude over the entire year (most of the values range between 0.3 and 0.8 ), since the main source of temperature fluctuations is at the surface. For the same reason, $\sigma_{T}$ is highly correlated to the sensible heat flux through the year (Fig. 1) and therefore $\sigma_{T} / T_{*}$ does not show any significant trend.

The integral scale $l_{c}$ has no significant seasonal variation (Fig. 10; Table 1), though vegetation experiences different conditions from stressed to well water-fed. The standard deviation $\sigma_{c}$ (Fig. 8) is in phase with the carbon dioxide flux (in absolute value) and evaporative fraction (see Fig. 1), with a slight decrease during the drying season. This decrease is due to less efficient air-plant exchanges when the vegetation is water-stressed, as is the case during the dry season.

At that point, it is difficult to incriminate entrainment as the main process affecting the humidity turbulent characteristics during the drying and moistening seasons since no yearlong dataset is available to estimate the entrainment rate at the PBL top above Nangatchori. 

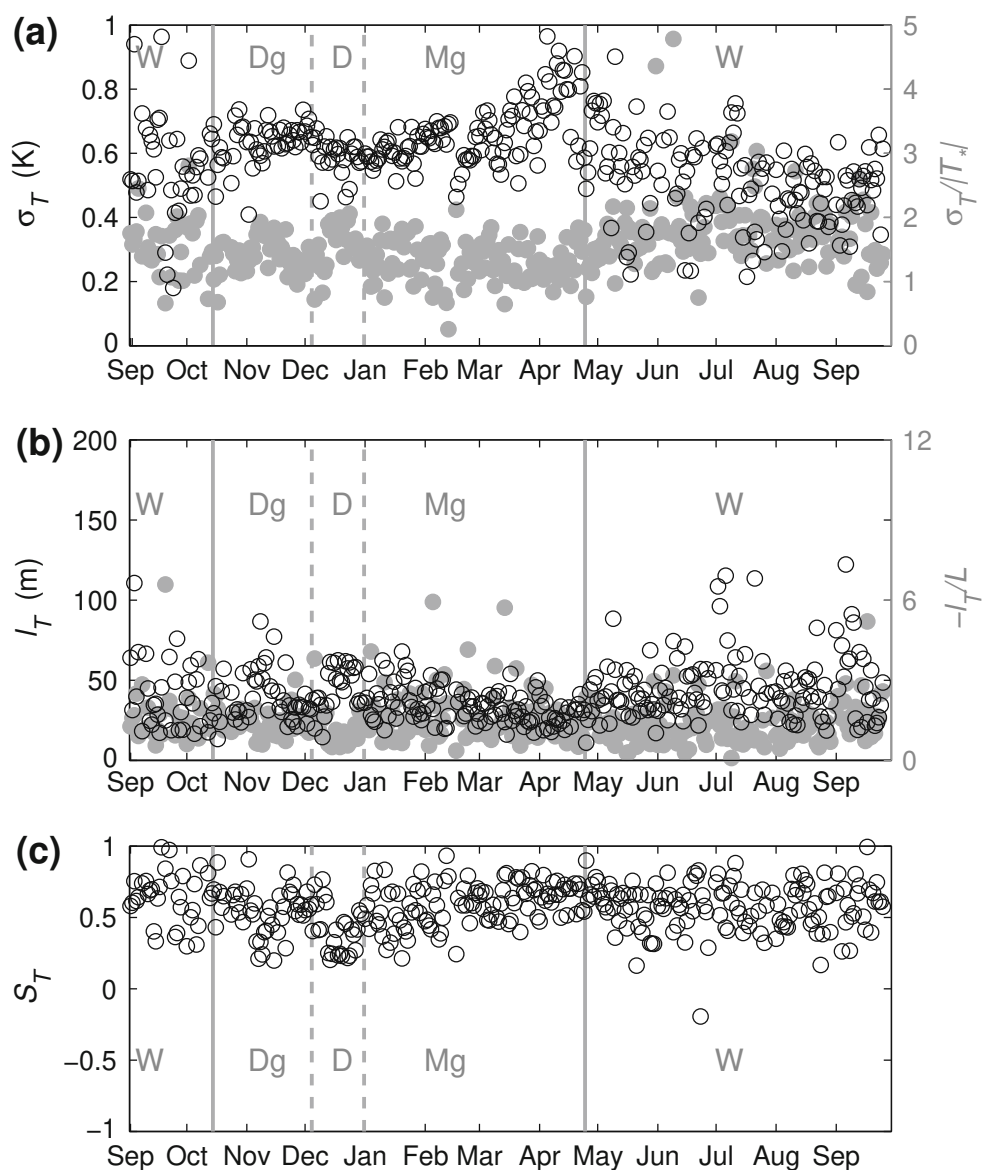

Fig. 9 Same as Fig. 8 for temperature $T$

The entrainment across the PBL top has been studied by Canut et al. (2010) with aircraft measurements above Niamey area during three special observation periods of AMMA experiment in summer 2006. Based on a PBL vertical exploration with stacked legs, these authors showed the existence of dry tongues arising from the SAL into the PBL. They characterized their morphology and pointed out their large contribution to variances and fluxes down to $z / z_{i}=0.4-0.6$. Saïd et al. (2010), using the same dataset, showed that the entrainment rate (defined as the ratio (in absolute value) of buoyancy flux at $z=z_{i}$ to that at the surface) decreases from June (end of moistening season in Niamey) to August (wet season in Niamey).

The case studies in Sect. 4 demonstrate the relationship between the entrainment impact down to the surface and $z_{i} / z_{s}$, the relative height of the PBL top to the shear level. Therefore, using the available measurements from radiosondes launched at Parakou at 1200 UTC, the vertical gradients in temperature $\left(\delta_{T}\right)$ and humidity $\left(\delta_{q}\right)$ at $z=z_{i}$ are plotted against $z_{i} / z_{s}$ in Fig. 11. The level $z=z_{i}$ is determined here as the top of the constant potential temperature layer, and the level $z=z_{s}$ from wind minimum and wind rotation criteria. The jumps in temperature and humidity are estimated right above $z=z_{i}$. Figure 11 confirms that, when 

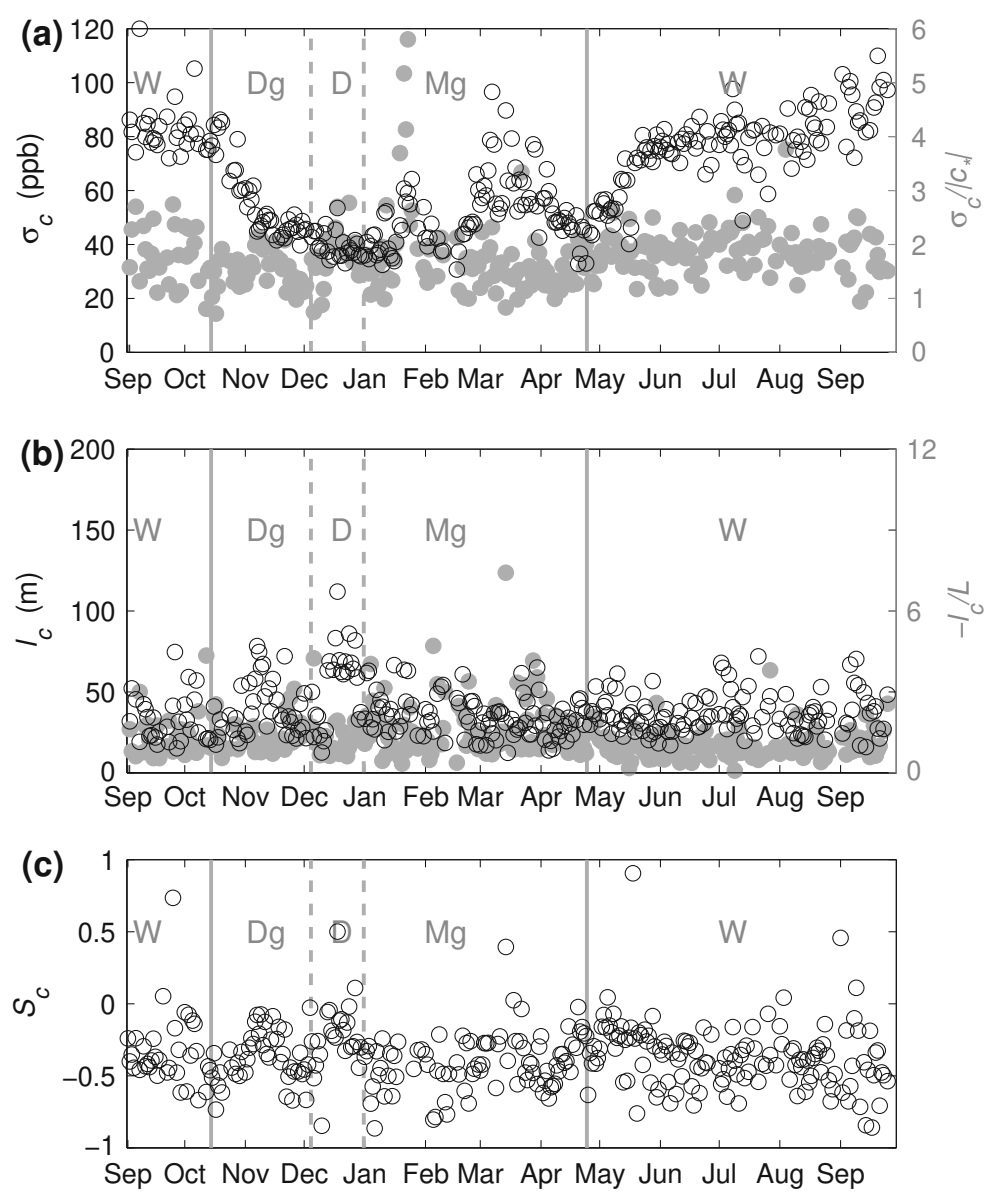

Fig. 10 Same as Fig. 8 for carbon dioxide $c$

$z_{i} / z_{s}$ is $<1$, which occurs primarily during the wet season, the temperature and humidity vertical gradients at $z=z_{i}$ are weak. The entrainment effect is then expected to be small, as observed in Figs. 8, 9 and 10. In April (moistening season) the PBL top is close to the shear level, inducing strong vertical gradients of temperature and humidity and more obvious impacts of the entrainment on the scalars down to the surface.

Some additional observations lend further support to the predominant role of the entrainment compared to surface spatial heterogeneity:

- High entrainment is consistent with the observed negative skewness $S_{q}$, indicating a top-down transport of drier parcels down to the surface.

- During the dry season, the horizontal advection of heterogeneities due to contrasting vegetation patches should affect the low frequencies of humidity and carbon dioxide signals in the same way. This is not observed since only humidity is affected. Similarly to Detto et al. (2008), we observe during daytime a lack of correlation between humidity and carbon dioxide during the $\mathrm{Dg}-\mathrm{Mg}$ season (not shown here), indicating that surface heterogeneity is not the main source of humidity variability. 
Table 1 Mean and standard deviation (SD) of

$l_{w}, l_{T}, l_{q}, l_{c}, l_{w t}$ and $l_{w q}$ for wet-dry (W-D) and drying-moistening (Dg-Mg) seasons. Units of $\mathrm{m}$

\begin{tabular}{lll}
\hline & W-D season & Dg-Mg season \\
\hline$l_{w}$ & 7 & 7 \\
Mean & 7 & 1 \\
SD & 3 & \\
$l_{T}$ & & 37 \\
Mean & 44 & 13 \\
SD & 21 & \\
$l_{q}$ & & 65 \\
Mean & 37 & 29 \\
SD & 13 & \\
$l_{c}$ & & 39 \\
Mean & 35 & 17 \\
SD & 13 & \\
$l_{w t}$ & & 7 \\
Mean & 7 & 3 \\
SD & 5 & 4 \\
$l_{w q}$ & & 3 \\
Mean & 5 & \\
SD & 3 & \\
\hline
\end{tabular}

\section{Conclusion}

The northward migration of the inter-tropical discontinuity from $5^{\circ} \mathrm{S}$ to $10^{\circ} \mathrm{N}$ to the Nangatchori site leads to a progressive setting of the cold and moist monsoonal flow below the warm and dry Harmattan flow. For an entire annual cycle, the surface experiences a wide range of conditions, from water-stressed vegetation in winter to well water-fed vegetation during the monsoon. Similarly, the low tropospheric vertical structure varies significantly during the year, leading to very different characteristics at the boundary-layer top. Thus, depending on the stage of the monsoonal progression (seasonal time scale) and on the diurnal development of the boundary layer, the predominant sources/sinks of temperature, humidity and carbon dioxide concentration can either be at the surface and/or at the PBL top.

From the monsoon study point of view, the importance of the parameter $z_{i} / z_{s}$, which gives the PBL position relative to the monsoon/Harmattan interface level, has been demonstrated. A value of this ratio close to one leads to strong variations in temperature and humidity at the PBL top. An entrainment impact is then observed on turbulent characteristics of the scalars near the surface. However, humidity is particularly affected at the seasonal scale, with fluctuation energy unrelated to the surface latent heat flux and an increase of the turbulent eddies length scale. The humidity is of primary importance in the monsoon system since its setting depends on many different processes, with spatial scales ranging from mesoscale to local scales. Our study shows that entrainment strongly affects the local scales down to the surface, where the moisture source for the whole system is located. The period during which the entrainment has a strong impact on the small-scale spatial repartition of moisture is quite long in north Benin but can vary from year to year. Two conditions must be satisfied in such situations: (i) a superposition of two very different flows (monsoon and Harmattan), (ii) an 

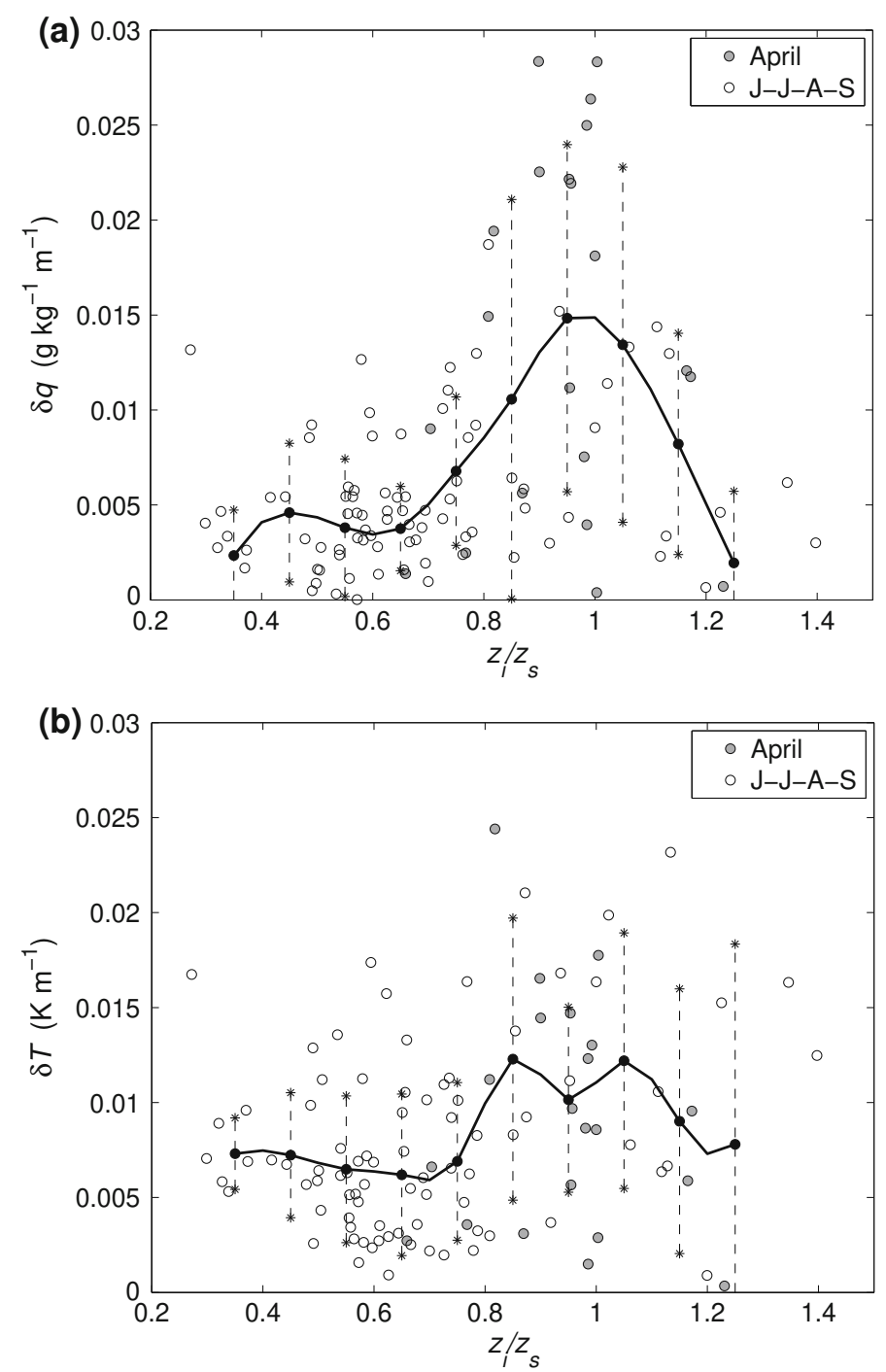

Fig. 11 Temperature and humidity vertical gradients $\left(\delta_{T}\right.$ and $\left.\delta_{q}\right)$ at the PBL top $\left(z_{i}\right)$ as a function of $z_{i} / z_{s}$, where $z_{s}$ is the shear level between the cold/moist monsoon and the warm/dry easterlies above. These variables are deduced from the radiosondes launched in Parakou at 1200 UTC in April, June, July, August and September 2006. Average values and standard deviations on $z_{i} / z_{s}$ bins are indicated by the solid line and the vertical bars, respectively

evaporative fraction high enough to allow the boundary-layer top to reach and overshoot the temperature jump between monsoonal and Harmattan flows. These conditions coincide during the drying and moistening periods, covering together 5 months at this latitude in 2006. Several studies have dealt with the interactions between the different components (PBL, monsoonal flow, Harmattan flow and African easterly jet) of the lower atmosphere during the monsoon. Canut et al. (2010), Kalapureddy et al. (2010) and Saïd et al. (2010) 
have highlighted the important features due to monsoon/Harmattan interactions and their impact either on the PBL or the African easterly jet. The current study places additional emphasis on the near-surface analysis, pointing out the impact of entrainment down to the surface along the seasonal cycle.

From the surface-layer point of view, Monin-Obukhov similarity theory, which relies on surface-scale-based normalization, shows very large scattering on moisture-related moments when the entrainment process dominates, whereas the other variables (vertical velocity, temperature and carbon dioxide) obey MOST whatever the observed extreme conditions at the surface and at the PBL top.

Acknowledgements Based on a French initiative, AMMA was built by an international scientific group and is currently funded by a large number of agencies, especially from France, UK, USA and Africa. It has been the beneficiary of a major financial contribution from the European Community's Sixth Frame-work Research Programme (Newsletter AMMA-France 06/12/2006). Detailed information on scientific coordination and funding is available on the AMMA international web site (http://www.amma-eu.org/). The authors would like also to thank the Centre National de la Recherche Météorologique at Météo-France for operating the UHF wind profiler in Nangatchori and B. Campistron for processing the data, D. Parker and A. Fink for coordinating the radiosounding operations, and ASECNA for carrying them out. Thanks to D. Ramier and B. Cappelaere for the processing they made on their own data acquired at the Niamey meso-site, which helped us in our study.

\section{Appendix: Spectra Selection}

Kaimal and Finnigan (1994) showed that the integral scale is related to the limit of the one-dimensional spectrum $S_{x}(f)$ when the frequency $f$ tends to zero:

$$
\lim _{f \rightarrow 0} S_{x}(f)=4 \overline{x^{\prime 2}} \frac{l_{x}}{U}
$$

Thus it is of primary importance, when estimating an integral scale, to be cautious about the existence of this limit and to check the convergence of the spectra at low frequency. In the well-mixed boundary layer, $w$ spectra are constant at low frequencies (or $f S_{x}(f)$ has a 1:1 slope), allowing us to estimate $l_{w}$ and $l_{w x}$ with a high level of accuracy. On the other hand, using various lengths of aircraft runs, Durand et al. (2000) found increasing length scales from $40 \mathrm{~m}$ to more than $1,000 \mathrm{~m}$ with increasing sample length from 11 to $180 \mathrm{~km}$ for temperature, moisture, horizontal velocity components, as well as for second-order moments in which $w$ is not involved.

For the near-surface measurements at the Nangatchori site, $w, T, q$ and $c$ spectra were systematically computed on 30-min samples. Figures 12 and 13 show examples of the 10001400 UTC averaged spectra $f S_{x}(f)$, where $x$ is $w, T, q$ or $c$, in April (the last month of the dry period) and May (the first month of the wet period) 2006, respectively. These spectra are normalized by the value of $f S_{x}(f)$ at $f=0.2 \mathrm{~s}^{-1}$, which is a frequency large enough to lie well within the inertial subrange but low enough to avoid noise contamination. $f S_{w}(f)$ usually shows a 1:1 slope at low frequencies, but $f S_{T}(f), f S_{q}(f)$ and $f S_{c}(f)$ do not. In April, when the surface is hot and dry and vegetation is water-stressed, the slopes of $f S_{q}(f)$ and $f S_{c}(f)$ at low frequencies are far from the 1:1, whereas $f S_{T}(f)$ exhibits slopes similar to those of $f S_{w}(f)$, and an expected shift of spectral energy peak towards lower frequencies compared to $f S_{w}(f)$. Lumley and Panofsky (1964) have observed that the location of the spectral peak for $T$ is intermediate between those of $w$ and $u$, possibly due to the relative influence of $u$ and $w$ on $T$, depending on the stability. 

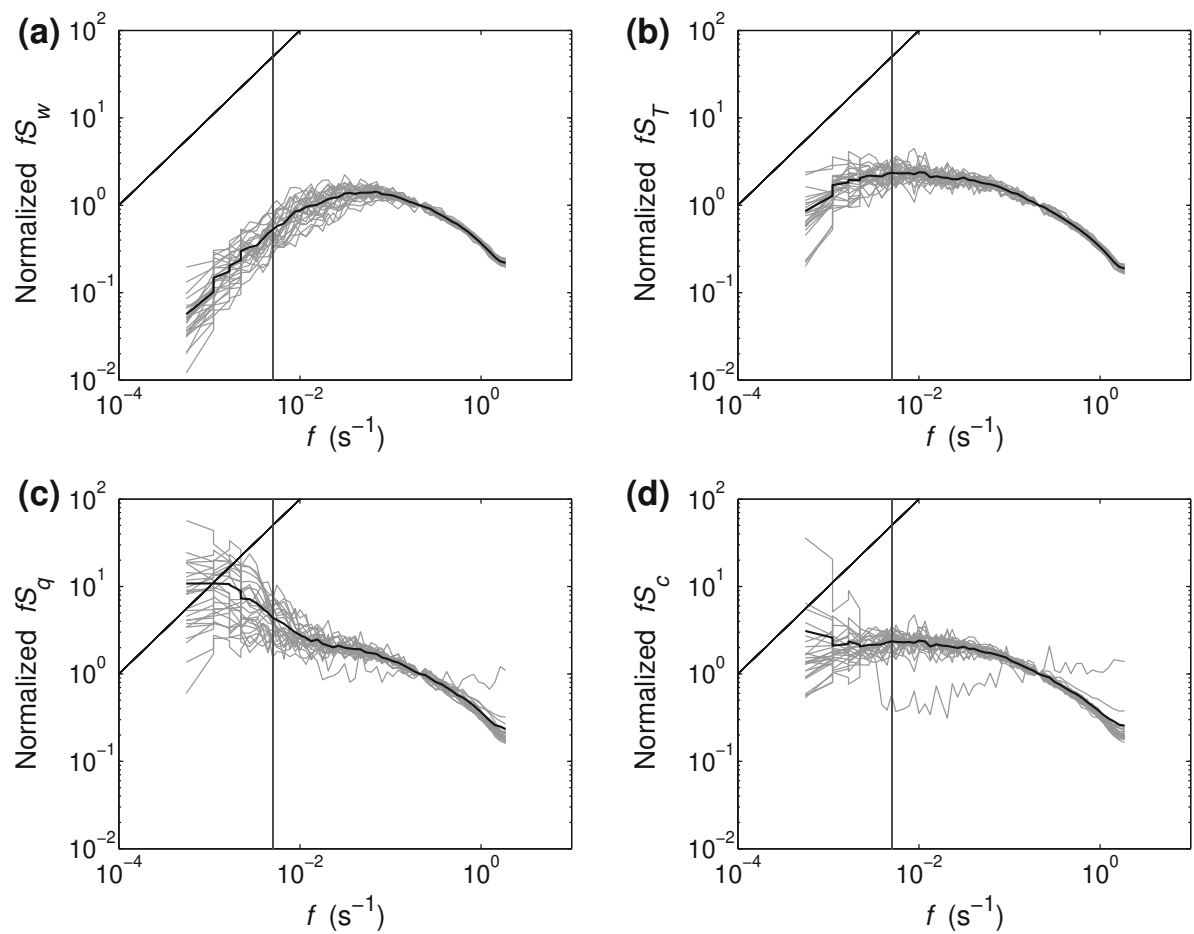

Fig. 12 1000-1400 UTC averages of normalized energy spectra (in grey) of a $w, \mathbf{b} T$, $\mathbf{c} q$ and $\mathbf{d} c$ for April 2006. The thick line stands for the monthly averaged energy spectra and the thin vertical line indicates the upper frequency of the range over which the spectra low-frequency slope is estimated $\left(5 \times 10^{-3} \mathrm{~s}^{-1}\right)$. The oblique line corresponds to a 1:1 slope

In the early wet season (May), when the surface is cooler and moister, the slopes of $f S_{q}(f)$ and $f S_{c}(f)$ spectra are closer to 1 than in April, and an increase in the scatter of $f S_{T}(f)$ slopes can be observed (Fig. 13). That is, the energy at low frequencies varies with the season and depends on the surface conditions.

The slopes of $f S_{w}(f), f S_{T}(f), f S_{q}(f)$ and $f S_{c}(f)$ over one decade $\left(5 \times 10^{-4}-5 \times\right.$ $10^{-3} \mathrm{~s}^{-1}$ ) calculated for each 30 -min sample are used to define a quality criterion of convergence for (3). The histograms of the slopes obtained over the whole year are displayed in Fig. 14. Table 2 presents the mean and standard deviation of the spectra slopes over the entire day (0000-2400 UTC) and during the 1000-1400 UTC period. $f S_{w}(f)$ has the expected slope of 1 on average, with a standard deviation of 0.84 . The small averages of $f S_{T}(f), f S_{q}(f)$ and $f S_{c}(f)$ slopes $(0.15,0.02$ and 0.08 , respectively) confirm the relevancy of checking the spectra before estimating the integral scales, since they imply that $f S_{x}(f)$ has no limit when $f \rightarrow 0$ for those scalars; that is, $l_{x}$ is not defined. Based on the mean and standard deviation of the $f S_{w}(f)$ slopes, we rejected samples for which the spectral slope is $\leq 0.4$ or $\geq 2$. The fraction of slopes verifying these selection criteria is larger during unstable conditions than for the whole day conditions (Table 2). Therefore, this selection results in retaining $71,54,44$ and $51 \%$ of the samples for $f S_{w}(f), f S_{T}(f), f S_{q}(f)$ and $f S_{c}(f)$, respectively, for the 1000-1400 UTC period considered for the integral scale computation. 

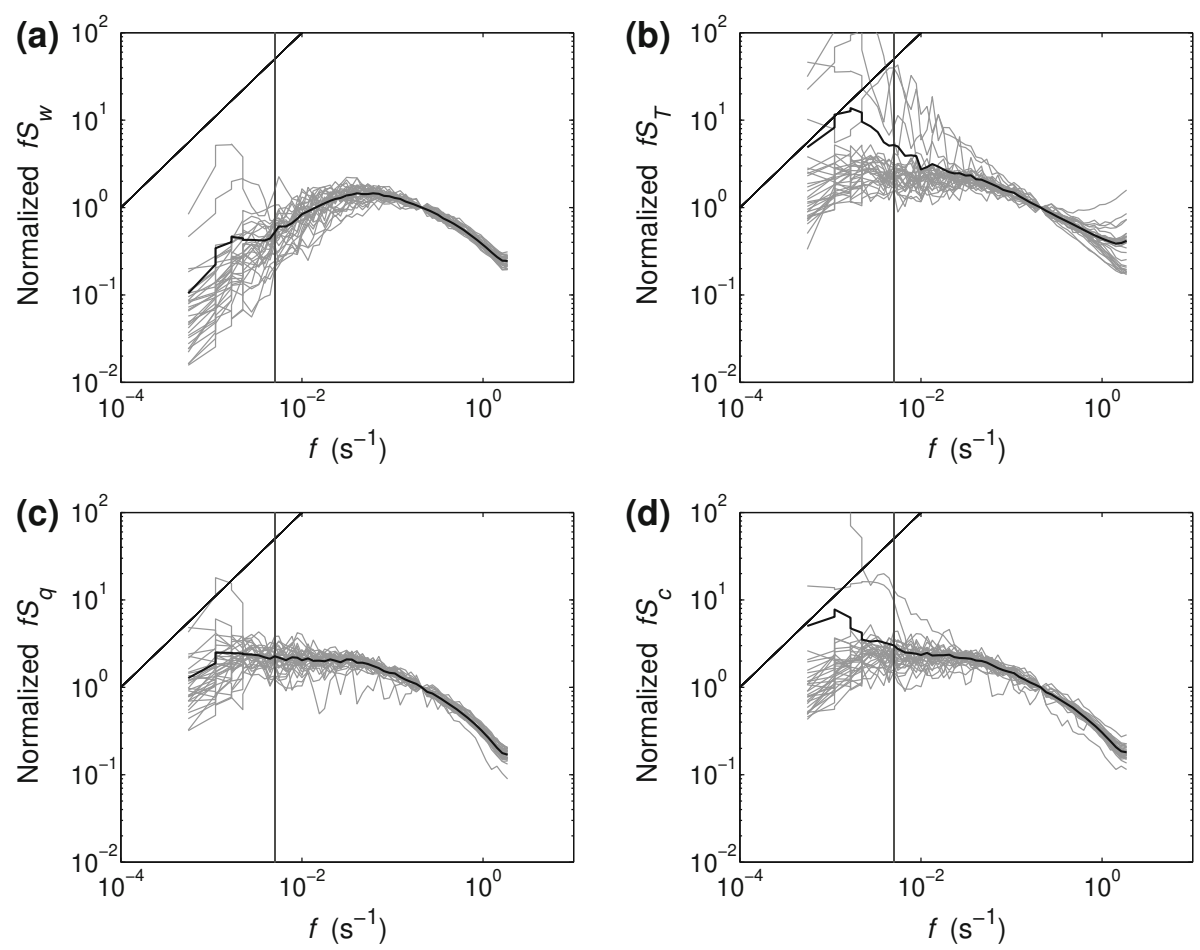

Fig. 13 Same as Fig. 12 for May 2006

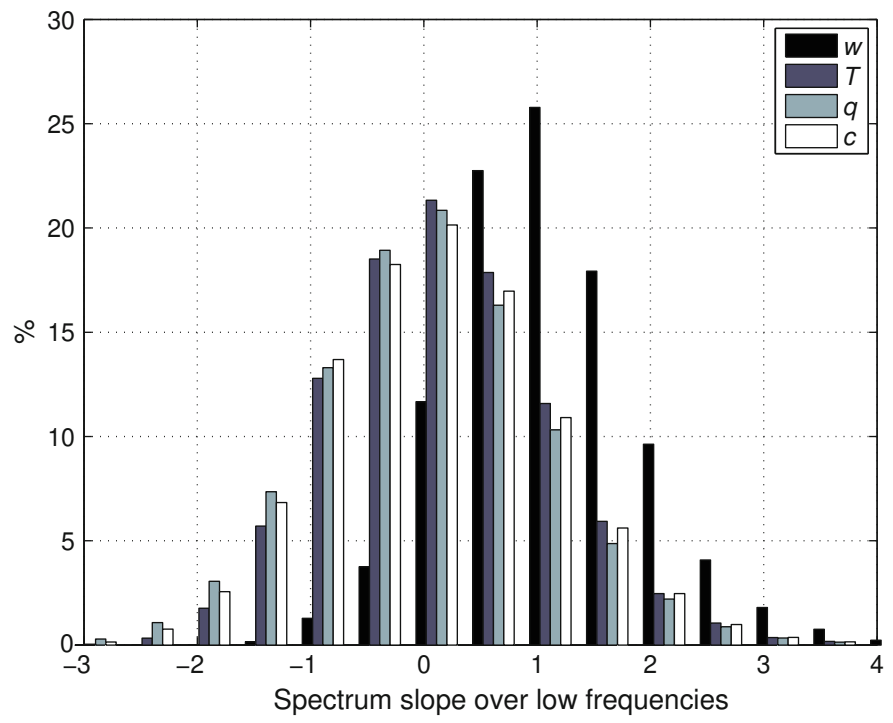

Fig. 14 Histograms of $f S_{w}(f), f S_{T}(f), f S_{q}(f)$ and $f S_{c}(f)$ slopes at low frequencies for 1 year (September 2005-September 2006) 
Table 2 Mean and standard deviation (SD) of the spectral slope of $w, T, q$ and $c$ when the whole day (0000-2400 UTC) or only around midday conditions (1000-1400) are considered. The percentages indicate the proportion of slopes that verify the selection criteria (values range between 0.4 and 2)

\begin{tabular}{llll}
\hline Spectral slope of & $0000-2400$ UTC & $1000-1400$ UTC \\
\hline$w$ & Mean & 1.11 & 1.24 \\
& SD & 0.84 & 0.79 \\
& $\%$ & 71 & 71 \\
$T$ & Mean & 0.15 & 0.69 \\
& SD & 0.95 & 0.88 \\
& $\%$ & 40 & 54 \\
& Mean & 0.02 & 0.47 \\
& SD & 1.00 & 0.89 \\
& $\%$ & 36 & 44 \\
$c$ & Mean & 0.08 & 0.65 \\
& SD & 1.00 & 0.89 \\
& $\%$ & 37 & 51
\end{tabular}

\section{References}

Andreas EL, Hill RJ, Gosz JR, Moore DI, Otto WD, Sarma AD (1998) Statistics of surface-layer turbulence over terrain with metre-scale heterogeneity. Boundary-Layer Meteorol 86:397-408

Angevine WM, White AB, Avery SK (1994) Boundary-layer depth and entrainment zone characterization with a boundary-layer profiler. Boundary-Layer Meteorol 68:375-385

Betts AK (2000) Idealized model for equilibrium boundary layer over land. J Hydrometeorol 1:507-523

Bock O, Bouin MN, Doerflinger E, Collard P, Masson F, Meynadier R, Nahmani S, Koitié M, Gaptia Lawan Balawan K, Didé F, Ouedraogo D, Pokperlaar S, Ngamini JB, Lafore JP, Janicot S, Guichard F, Nuret M (2008) West African Monsoon observed with ground-based GPS receivers during African Monsoon Multidisciplinary Analysis (AMMA). J Geophys Res 113:D21105. doi:10.1029/2008JD010,327

Canut G, Lothon M, Saïd F, Lohou F (2010) Observation of entrainment at the interface between monsoon flow and saharan air layer. Q J Roy Meteorol Soc. doi:10.1002/qj.471

Conzemius RJ, Fedorovich E (2008) A case study of convective boundary layer development during IHOP2002: numerical simulations compared to observations. Mon Weather Rev 136:2305-2320

Couvreux F, Guichard F, Redelsperger JL, Masson V (2007) Negative water vapour skewness and dry tongues in the convective boundary layer: observations and LES budget analysis. Boundary-Layer Meteorol 123:269-294

Crum TD, Stull RB (1987) Field measurements of the amount surface layer air versus height in the entrainment zone. J Atmos Sci 44:2743-2753

de Arellano JVG, Gioli B, Miglietta F, Jonker HJJ, Baltink HK, Hutjes RWA, Holtslag AAM (2004) Entrainment process of carbon dioxide in the atmospheric boundary layer. J Geophys Res 109:D18110

De Roode SR, Duynkerke PG, Jonker HJJ (2004) Large-eddy simulation: how large is large enough?. J Atmos Sci 61:403-421

Detto M, Katul G, Mancini M, Montaldo N, Albertson JD (2008) Surface heterogeneity and its signature in higher-order scalar similarity relationships. Agric For Meteorol 148:902-916

Doviak RJ, Zrnic DS (1993) Doppler radar and weather observations. Academic Press, San Diego

Druilhet A, Frangi J, Guedalia D, Fontan J (1983) Experimental studies of the turbulent structure parameters of the convective boundary layer. J Clim Appl Meteorol 22:594-608

Durand P, Thoumieux F, Lambert D (2000) Turbulent length-scales in the marine atmospheric mixed layer. Q J Roy Meteorol Soc 126:1889-1912

Jacoby-Koaly S, Campistron B, Bernard S, Bénech B, Girard-Ardhuin F, Dessens J (2002) Turbulent dissipation rate in the boundary layer via UHF wind profiler Doppler spectral width measurements. BoundaryLayer Meteorol 103:361-389

Janicot S, Sultan B (2007) The large-scale context of the West African Monsoon in 2006. Exch CLIVAR Newslett 12(2):11-17

Jonker HJJ, Duynkerke PG, Cuijpers JWM (1999) Mesoscale fluctuations in scalars generated by boundary layer convection. J Atmos Sci 56:801-808 
Jonker HJJ, de Arellano JVG, Duynkerke PG (2004) Characteristic length scale of reactive species in a convective boundary layer. J Atmos Sci 61:41-56

Kaimal JC, Finnigan JJ (1994) Atmospheric boundary layer flows. Oxford University Press, New York, 289 pp

Kalapureddy M, Lothon M, Campistron B, Lohou F, Saï F (2010) Wind profiler analysis of the African easterly jet in relation with the boundary layer and the Saharan heat-low. Q J Roy Meteorol Soc. doi:10. 1002/qj.494

Lafore JP, Flamant C, Giraud F, Guichard F, Knipperts P, Mahfouf JF, Mascart P, Williams E (2010) Introduction to the AMMA special issue on: advances in understanding processes over west Africa through the AMMA field campaign. Q J Roy Meteorol Soc. doi:10.1002/qj.583

Lenschow DH, Stankov BB (1986) Length scales in the convective boundary layer. J Atmos Sci 43:1198-1209

Lenschow DH, Wulfmeyer V, Senff C (2002) Measuring second- through fourth-order moments in noisy data. J Atmos Ocean Technol 17:1330-1347

Lothon M, Couvreux F, Donier S, Guichard F, Lacarrère P, Noilhan J, Saïd F (2007) Impact of the coherent eddies on the airborne measurements of vertical turbulent fluxes. Boundary-Layer Meteorol 124:425-447

Lothon M, Saïd F, Lohou F, Campistron B (2008) Observation of the diurnal cycle in the low troposphere of west Africa. Mon Weather Rev 136:3477-3500

Lumley JL, Panofsky HA (1964) The structure of atmospheric turbulence. Inter-Science, New York, 239 pp

Mahrt L (1991) Boundary-layer moisture regimes. Q J Roy Meteorol Soc 117:151-176

Moene AF, Michels BI, M HA (2006) Scaling variances of scalars in a convective boundary layer under different entrainment regimes. Boundary-Layer Meteorol 120:257-274

Nicholls S, LeMone MA (1980) The fair boundary layer in gate: the relationship of subcloud fluxes and structure to the distribution and enhancement of the cumulus cloud. J Atmos Sci 37:2051-2067

Parker DJ, Burton RR, Diongue-Niang A, Ellis RJ, Felton MA, Taylor CM, Thorncroft CD, Bessemoulin P, Tompkins AM (2005) The diurnal cycle of the West African Monsoon circulation. Q J Roy Meteorol Soc 131:2839-2860

Ramier D, Boulain N, Cappelaere B, Timouk F, Rabanit M, Lloyd CR, Boubkraoui S, Métayer F, Descroix L, Wawrzyniak V (2009) Towards an understanding of coupled physical and biological processes in the cultivated Sahel-1. Energy and water. J Hydrol 375:204-216

Redelsperger J, Thorncroft C, Diedhiou A, Lebel T, Parker DJ, Polcher J (2006) African Monsoon Multidisciplinary Analysis (AMMA): an international research project and field campaign. Bull Am Meteorol Soc 87:1739-1746

Saïd F, Canut G, Durand P, Lohou F, Lothon M (2010) Seasonal evolution of the boundary-layer turbulence measured by aircraft during AMMA 2006 special observation period. Q J Roy Meteorol Soc. doi:10. 1002/qj.475

Santanello JA, Friedl MA, Ek MB (2007) Convective planetary boundary layer interactions with the land surface at diurnal time scale: diagnostics and feedbacks. J Hydrol 8:1082-1097

Stull RB (1988) An introduction to boundary layer meteorology. Kluwer, Dordrecht, 666 pp

Sultan B, Janicot S (2003) The West African Monsoon dynamics. Part II: the 'pre-onset' and the 'onset' of the summer monsoon. J Clim 16:3407-3427

Timouk F, Kergoat L, Mougin E, Lloyd CR, Cohard JM, de Rosnay P, Hiernaux P, Demarez V, Taylor CM (2009) Response of surface energy balance to water regime and vegetation development in a Sahelian landscape. J Hydrol 375:178-189

Webb E, Pearman G, Leuning R (1980) Correction of flux measurements for density effects due to heat and water-vapor transfer. Q J Roy Meteorol Soc 106:85-100 